\title{
DNA-testing for BRCA1/2 prior to genetic counselling in patients with breast cancer: design of an intervention study, DNA-direct
}

\author{
Aisha S Sie ${ }^{1}$, Liesbeth Spruijt ${ }^{1 \dagger}$, Wendy AG van Zelst-Stams ${ }^{1 \dagger}$, Arjen R Mensenkamp ${ }^{1}$, Marjolijn J Ligtenberg ${ }^{1}$,
} Han G Brunner ${ }^{1}$, Judith B Prins ${ }^{2}$ and Nicoline Hoogerbrugge ${ }^{1 *}$

\begin{abstract}
Background: Current practice for patients with breast cancer referred for genetic counseling, includes face-to-face consultations with a genetic counselor prior to and following DNA-testing. This is based on guidelines regarding Huntington's disease in anticipation of high psychosocial impact of DNA-testing for mutations in BRCA1/2 genes. The initial consultation covers generic information regarding hereditary breast cancer and the (im)possibilities of DNA-testing, prior to such testing. Patients with breast cancer may see this information as irrelevant or unnecessary because individual genetic advice depends on DNA-test results. Also, verbal information is not always remembered well by patients. A different format for this information prior to DNA-testing is possible: replacing initial face-to-face genetic counseling (DNA-intake procedure) by telephone, written and digital information sent to patients' homes (DNA-direct procedure).
\end{abstract}

Methods/design: In this intervention study, 150 patients with breast cancer referred to the department of Clinical Genetics of the Radboud University Nijmegen Medical Centre are given the choice between two procedures, DNA-direct (intervention group) or DNA-intake (usual care, control group). During a triage telephone call, patients are excluded if they have problems with Dutch text, family communication, or of psychological or psychiatric nature. Primary outcome measures are satisfaction and psychological distress. Secondary outcome measures are determinants for the participant's choice of procedure, waiting and processing times, and family characteristics. Data are collected by self-report questionnaires at baseline and following completion of genetic counseling. A minority of participants will receive an invitation for a 30 min semi-structured telephone interview, e.g. confirmed carriers of a BRCA1/2 mutation, and those who report problems with the procedure.

Discussion: This study compares current practice of an intake consultation (DNA-intake) to a home informational package of telephone, written and digital information (DNA-direct) prior to DNA-testing in patients with breast cancer. The aim is to determine whether DNA-direct is an acceptable procedure for BRCA1/2 testing, in order to provide customized care to patients with breast cancer, cutting down on the period of uncertainty during this diagnostic process.

Trial registration: The study is registered at the Dutch Trial Registry www.trialregister.nl (NTR3018).

Keywords: Hereditary, Breast cancer, BRCA, Genetic, Counseling, DNA

\footnotetext{
* Correspondence: N.Hoogerbrugge@gen.umcn.nl

${ }^{\dagger}$ Equal contributors

'Department of Human Genetics, Radboud University Nijmegen Medical

Centre, Nijmegen, the Netherlands

Full list of author information is available at the end of the article
}

\section{Ciomed Central}

(c) 2012 Sie et al.; licensee BioMed Central Ltd. This is an Open Access article distributed under the terms of the Creative Commons Attribution License ( http://creativecommons.org/licenses/by/2.0), which permits unrestricted use, distribution, and reproduction in any medium, provided the original work is properly cited. 


\section{Background}

Patients with breast cancer at high risk of an underlying hereditary predisposition face a time-consuming diagnostic process of several months: it might be helpful to be able to cut down on this long period of uncertainty and provide information applicable to their personal situation as early as possible. Having personal experience with breast cancer, these patients are likely to have enhanced personal risk estimates, thus a higher expectation for protective actions such as longer or more intensive surveillance [1]. Should they carry a pathogenic mutation in either the $B R C A 1$ or $B R C A 2$ gene, these patients do have a considerable long term risk for developing a second primary breast cancer (either ipsi- or contralateral) of up to 60\% [2-4]. Women recently diagnosed with breast cancer may want to take their BRCA1/2 status into consideration for their choice of surgical treatment (i.e. breast-conserving with radiotherapy versus ipsi/contralateral mastectomy) and, in the near future, chemotherapy (i.e. PARP-inhibitors) [5-10]. BRCA1/2 mutation carriers face an additional risk of ovarian cancer ranging from $20-60 \%$ for $B R C A 1$ and $2-20 \%$ for $B R C A 2$ [2-4]. As screening for ovarian cancer through yearly serum CA-125 measurements and transvaginal ultrasound has proven to be ineffective [11-13], clinicians strongly recommend prophylactic bilateral salpingoophorectomy (pBSO) around the age of 35 to 40 years [13]. pBSO reduces the risk of ovarian cancer by $80-90 \%$, and in unaffected premenopausal women simultaneously reduces breast cancer risk by $50 \%[14,15]$.

Patients with breast cancer often express concern and uncertainty regarding the risk of breast cancer for their unaffected relatives, especially their sisters and daughters [16]. For unaffected relatives carrying a BRCA1/2 mutation, cumulative breast cancer risk at the age of 70 years ranges from $40-80 \%$ [2-4]. At the age of 25 years, they may choose between an intensive breast cancer screening program consisting of yearly MRI scans, mammography and clinical breast examinations $[17,18]$ or undergoing prophylactic surgery, reducing the risk for breast cancer by $90 \%$ [19-21]. Some carriers may still be at an age to be confronted with childbearing conflicts [22]. These are only a few of the life-changing decisions for both patients with breast cancer and their relatives dependent on the results of DNA-testing, which may or may not confirm the presence of a genetic predisposition for breast and ovarian cancer. A previous study in Dutch patients being evaluated for possible breast cancer showed that these patients experienced the period before the final diagnosis as the most stressful, regardless of whether they had received a benign or cancer diagnosis afterwards [23]. This same principle likely applies to $B R C A 1 / 2$ testing. Reducing the period of uncertainty in the diagnostic process and offering various forms of information might help substantially.
Another attempt to speed up the diagnostic process concerning hereditary cancer was previously introduced in the evaluation of hereditary colon cancer in the Netherlands. Pathologists are now able to test tumor material of patients younger than 50 years for microsatellite instability (MSI) and immunohistochemical staining of gene products, which may reveal a high a priori risk for an underlying genetic predisposition, without prior consultation of a genetic counselor. If these characteristics are present, patients are referred for further evaluation by a genetic counselor $[24,25]$. This so-called MIPA procedure (MSI-test by pathologists) is seen by patients as a valuable addition to the diagnostic process of hereditary colon cancer, without feeling either overwhelmed or underinformed, nor showing increased levels of psychosocial distress [26-28].

Such an intervention may also be applicable to patients with breast cancer. As there is no equivalent of tumor material testing in hereditary breast cancer, alternatives for modification must be found within the current diagnostic process. Genetic testing for hereditary breast cancer includes genetic counseling both prior to and following DNA-testing, based on guidelines regarding presymptomatic testing for Huntington's disease (HD) [29-31]. This approach had been adopted for hereditary breast cancer due to concerns about the psychological consequences of $B R C A 1 / 2$ genetic susceptibility testing [32]. However, extensive prior research shows there is no significant long term psychological impact: after an initial increase following BRCA1/2 testing, psychosocial distress returns to pretesting levels over time [33-39]. Therefore, in the case of hereditary breast cancer where protective measures are possible, it may not be necessary to adhere to such a strict counseling protocol as defined for an untreatable neurodegenerative disorder such as HD [32]. Patients with breast cancer express the most interest in answers regarding their personal situation: Is my breast cancer of hereditary origin and what are my children's risks [submitted data by S. Salemink]? Answers to these questions cannot be given until the results of DNA-testing are known. During the initial face-to-face consultation, patients are provided with general information regarding hereditary breast cancer, DNAtesting and possible consequences, prior to actual DNAtesting. Patients consider this generic information less relevant than the personal advice in the second consultation post DNA-testing and may thus experience this intake as an unnecessary delay [40]. It is also widely known that about 40 to $80 \%$ of verbal information is immediately forgotten by patients [41]. A recent study in Canada offered a group of Jewish women DNA-testing through written and telephone invitation. The majority of these women had positive experiences with this approach and considered it to be effective [42]. Providing patients with alternative means to educate themselves regarding hereditary breast cancer and DNA-testing, prior to their decision to undergo 
testing, might improve patient recollection of medical information as well as increase patient participation.

Therefore, this study offers patients with breast cancer the choice of replacing the initial face-to-face consultation prior to DNA-testing (usual care DNA-intake procedure) by a home information package including telephone, written and digital information consisting of a website and educational movie (DNA-direct procedure). DNA-testing will thus be performed prior to genetic counseling, contrary to current practice. At the first face-to-face contact, counselors will be able to disclose DNA-results and customized advice to patients. This eliminates extraneous information which is not applicable to the individual patient, and provides patients with the information they desire in a quick and patient-centric manner.

The aim of this intervention study is to compare this new DNA-direct procedure to current practice (DNA-intake procedure). The effects of the DNA-direct procedure on the experience and psychosocial distress on patients with breast cancer, as well as the speed and quality of genetic advice, will be evaluated. The hypothesis is that undergoing the DNA-direct procedure does not lead to increased levels of psychosocial distress as compared to the usual care DNAintake procedure, with equal levels of patient satisfaction plus shorter waiting and processing times. A trend similar to traditional $B R C A 1 / 2$ testing - a short term increase in distress, falling back to pre-testing levels over time [33-39] - is expected in the DNA-direct procedure. This would make DNA-direct an acceptable procedure for patients with breast cancer undergoing genetic testing, with the goal of more customized care, and a shorter period of uncertainty. Moreover, it would facilitate taking genetic advice into account for the treatment and follow-up of breast cancer.

\section{Methods/design Design}

The study examines the effect of the DNA-direct procedure on the experience and psychological distress of patients with breast cancer as well as several secondary outcome measures, including waiting and processing times, as compared to the current DNA-intake procedure. Two groups will be compared: the intervention group, who choose to undergo the DNA-direct procedure, and the control group, who will receive care as usual (DNA-intake procedure). Participants may choose freely between the DNA-direct versus DNA-intake procedures. This study is not randomized due to the wish to evaluate whether there is indeed a desire for the proposed DNA-direct procedure amongst patients with breast cancer, and to evaluate the reasons stated for preferring one procedure over the other.

\section{Ethical consideration}

The study has been approved by the medical ethical committee of the Radboud University Nijmegen Medical
Centre. Full medical ethical approval has been obtained in July 2011.

\section{Study sample}

All female patients previously or currently diagnosed with breast cancer and referred to the department of Clinical Genetics of the Radboud University Nijmegen Medical Centre from August 9th 2011 are eligible for inclusion. Recruitment will continue until the desired total of 150 participants is reached. Patients who have problems reading Dutch text, problems with family communication or problems of psychological/psychiatric nature (including current use of related medication) will be excluded.

\section{Recruitment}

Patients are sent a written letter by a trained doctor announcing a phone call, in which the two choices of procedure are explained (DNA-intake for a face-to-face intake consultation prior to DNA-testing, versus DNAdirect for a home package of telephone, written and digital information) and exclusion criteria are checked. The aim of this telephone approach is triage: by checking for exclusion criteria such as psychological problems, patients who aren't deemed suitable for DNA-direct (due to its dependency on the patient's own decision making ability) are filtered out and instead invited for a regular intake consultation, where further psychosocial support is immediately available prior to DNA-testing. Genetic counseling is not offered by phone: questions of this nature are deferred to the personal consultations. The triage phone call has been thoroughly practiced (over 20 times) by the involved doctor with people both specialized and not specialized in clinical genetics.

All patients receive the same two questionnaires, one at inclusion (baseline) and one after completion of the chosen genetic counseling procedure (follow-up). Patients who are confirmed carriers of a BRCA1/2 mutation, patients reporting problems with the chosen procedure, and randomly selected $(n=10)$ patients will be invited for a $30 \mathrm{~min}$ semi-structured telephone interview.

\section{$B R C A 1$ and $B R C A 2$ genetic testing}

The coding sequences and intron/exon boundaries of BRCA1 and BRCA2 are analyzed by sequence analysis (primer sequences available on request). Gross deletions and duplications in the BRCA1 gene are detected by multiplex ligation-dependent probe amplification (MRCHolland, Amsterdam, kit P002-C2). All findings are confirmed by an independent test.

\section{Intervention}

Patients who choose the DNA-direct procedure, receive a home informational package including an informational letter, a link to a website including a short educational 
movie about hereditary breast cancer and DNA-testing. Also included are two EDTA blood vials with informed consent and family history forms. Patients are instructed to call their family doctor assistant to ask where to have their blood drawn, then return the vials plus signed forms in the appropriate return package. An appointment for a personal consultation to disclose results is set 8 weeks after DNA-testing has commenced.

All patients (whether they choose DNA-direct or DNA-intake) are seen by one of five selected genetic counselors, each of whom has extensive experience in genetic counseling for hereditary cancer. These counselors have had multiple meetings in order to structure the DNA-direct consultations as follows: If no mutation is found, further screening advice is formulated based on familial risk scores: FHAT [43], Myriad [44] and Claus/ van Asperen $[45,46]$. Further evaluation of family history and features of other hereditary cancer syndromes may be required. In the case of a pathogenic BRCA1 or $B R C A 2$ mutation, this result is disclosed immediately, first allowing the patient to react, followed by an explanation of the consequences, including prevention measures and family evaluation. If considered necessary, a second consultation is offered for further genetic counseling. All confirmed $B R C A 1 / 2$ carriers will be approached by a social worker to extend psychosocial support if needed, as in usual care.

\section{Study outcomes}

Participants are asked to fill out a questionnaire twice: at baseline and following the conclusion of genetic counseling and/or testing (follow-up). Some measures are used in both questionnaires, while others are only included in either baseline or follow-up.

\section{Primary outcomes \\ Choice of procedure}

Percentages of patients choosing one procedure over the other (ratio between the two groups) is determined to assess the desirability of the new DNA-direct procedure.

\section{Psychological burden (baseline and follow-up)}

Quality of Life To measure global health-related quality of life (QoL), two items scored on a scale of 1-7 were selected from the EORTC-Q30. The full EORTC-Q30 has been widely used and validated for cancer research [47]. The two global QoL items have an excellent internal consistency as proven by the reported Cronbach's $\alpha$ of 0.91 [48].

General health The 12-item version of the General Health Questionnaire (GHQ-12) is used as a measure of general psychological distress, using GHQ-scoring of
$0,0,1,1$ per item (range $0-12$ ) with a threshold of $\geq 4$ to identify 'caseness', recommended for patients with breast cancer. The GHQ-12 is the shortest version of all GHQs and recommended for research use, with good internal consistency (Cronbach's $\alpha=0.82$ - 0.86) [49-51].

Cancer specific distress The Impact of Event Scale (IES) measures cancer specific distress [52,53] and is included in baseline once using genetic predisposition for cancer as the distressing event, once using breast cancer. For follow-up, only genetic predisposition is included. The IES consists of 15 items, each scored $0,1,3,5$. A total score of $9-25$ or $\geq 26$ reflects moderate or serious adaptation difficulties respectively. The Dutch version of the IES has a good internal consistency with a Cronbach's $\alpha$ of 0.87 to 0.96 [53].

Risk perception Risk perception of a genetic predisposition for breast cancer, as well as breast cancer recurrence, is measured on a scale of 0-100.

Cancer worry scale To measure fear of cancer recurrence, the 8-item Cancer Worry Scale (CWS) is included, which has previously been used in studies among cancer patients. Each item is scored 1,2,3,4 from 1 'almost never' to 4 'almost always', the total score ranging from 8-32. It has a good internal consistency with a Cronbach's $\alpha$ of 0.80 [54-56].

\section{Experiences with genetic counseling (follow-up)}

Decisional conflict The difficulty of decision-making, in this study defined as whether or not to undergo genetic testing, is assessed using the traditional format of the Decisional Conflict Scale; 1 item ("I expect to stick to my decision") is left out as it is not applicable to DNAtesting [57-59]. 15 items scored 0,1,2,3,4 from 0 'strongly agree' to 4 'strongly disagree' remained, including "I am satisfied with my decision" which is also used separately for overall satisfaction. Scores are summed, divided by 15 and multiplied by 25 , resulting in a range from 0 to 100. Scores below 25 are considered as 'no decisional conflict', between 25 and 37.5 as 'moderate conflict' and exceeding 37.5 as 'severe conflict'. The DCS has good internal consistency exceeding 0.78 [57-59].

Satisfaction with choice Knowledge of hereditary breast cancer following versus prior to the chosen genetic counseling procedure, as well as the amount and quality of information received, is rated on a scale of 1-6. Participants answer 'yes', 'no' or 'don't know' for choosing DNA-testing and/or DNA-direct if given a second chance or asked to give advice to other women in a similar situation. 
Satisfaction with genetic counseling The Dutch National Institute for Public Health and the Environment (RIVM) developed a standard questionnaire to measure satisfaction with the service (18 items) and information (8 items) expected of a genetic counselor. Each item is scored on a Likert-scale 1-4, total scores range from 26-104. Open-ended questions evaluate positive/negative experiences during the chosen genetic counseling procedure.

\section{Secondary outcomes \\ General information (baseline)}

Demographical and breast cancer information Data are gathered on age, education level, work status, marital and parental status, cancer status, medical information need (scale 1-10), use of breast cancer information resources and type of information previously given by their referring physician.

Empowerment (baseline) Empowerment is the process in which patients discover and utilize their own power, which will be measured using the Cancer Empowerment Questionnaire (CEQ). It consists of 40 items, each scored on a Likert-scale of 1-5 (1 'strongly disagree', 5 'strongly agree'). Four factors are identified: 'Personal Strength', 'Social Support,' 'Community' and 'Health Care'. A good internal consistency (Cronbach's $\alpha=0.94$ ) was demonstrated for all four factors and the total Empowerment scale [60].

\section{Experiences with genetic counseling and testing (follow-up)}

Choice of procedure Participants describe reasons for choosing DNA-direct or DNA-intake.

Family relations Three categories of family members are defined: 1) nuclear family, being partner and/or children; 2) family of origin, being parents, brothers and/or sisters; and 3) aunts and female cousins on the family side where breast cancer is prevalent, being the second generation relatives most likely to be affected by genetic testing of the patient. Participants report the frequency of contact with each category of relatives, as well as indicate the quality of their relationship on a scale of 1-10.

Family communication For each above-mentioned relative, participants indicate whether, and if so, when (directly after information, just before DNA-result, after DNA-result) and how often (on a scale of 1-5), they had spoken to this relative about hereditary breast cancer. Also included is the Openness to Discuss Hereditary Cancer in the Family scale (ODHCF) which consists of 7 items each scored 1,2,3,4 with a range 7-24: once for the nuclear family $(\alpha=0.79)$ and once for the family of origin $(\alpha=0.93)[61]$.

\section{Other measures}

Waiting and processing times, as well as family pedigree characteristics, are also gathered.

\section{Sample size calculation}

For this intervention study, participants are not randomized into groups, but given their own choice. This leads to certain complications when it comes to a formal power calculation. First, the ratio between the two procedures is unknown: this may either be balanced (50\% versus $50 \%$ ) or unbalanced (e.g. $20 \%$ versus $80 \%$ ). Second, due to not randomizing, the results will have to be corrected for multiple confounders, which are not all known at this point. The sample size, based on aforementioned ratio between both groups (choice of procedure), needs to be large enough to be able to integrate these confounders into a regression model. Using a power of $80 \%$ and a two-tailed probability level for statistical significance testing of 0.05 , while taking into account group ratios ranging from balanced ( $50 \%$ versus $50 \%$ ) versus unbalanced (to an estimated maximum of $20 \%$ versus $80 \%$ ), the total sample size has been set to 150 patients with breast cancer.

\section{Statistical analysis}

To compare general characteristics, baseline and followup results between the intervention versus control group, the unpaired $t$-test will be used for continuous variables, Mann-Whitney $U$ test for non-parametric variables and chi-square test for dichotomous variables. For the comparison of baseline versus follow-up results within each group, the paired $t$-test will be used for continuous, Wilcoxon test for non-parametric and McNemar's test for dichotomous variables. Multivariate analysis will consist of a regression model using the follow-up results as outcome (dependent) variables, to be compared between the intervention versus control groups as independent variables, with the baseline results as covariates supplemented by variables that were found to be statistically significant in previous univariate analyses. The probability level for statistical significance testing is set at 0.05 (two-tailed). The SPSS 18.0 statistical package will be used to analyze the data.

\section{Discussion}

Considering today's call for more patient participation in medical decision-making, the convenience of taking up information and drawing blood close to home, paired with customized advice from the very first consultation, might appeal to patients. Replacing the face-to-face intake consultation with a genetic counselor by a home informational package of telephone, written and digital information might speed up the diagnostic process of hereditary breast cancer and reduce extraneous information. For example, this would allow patients to go over 
this information at their own convenience and in their own homes. It could possibly reduce travel efforts to a hospital as well as time conflicts with breast cancer therapy.

However, there are certain downsides compared to traditional genetic testing. All patients with breast cancer referred to clinical genetics by their treating physician are eligible for the DNA-direct procedure. This means that even those patients who would not normally fulfill criteria for $B R C A 1 / 2$ testing are now able to have their blood drawn for DNA-testing, regardless of those criteria. In the DNA-intake procedure, patients who do not fulfill the aforementioned criteria will not be offered further DNA-testing. This may lead to a selection bias. Our intention is to compare DNA-direct to current practice: adhering to these criteria is the current practice and must be reflected in the DNA-intake procedure.

Additionally, genetic counselors must adjust their counseling styles to the disclosure of the DNA-results being the first order of business, without having built up a counselorpatient relationship beforehand. New information might come forward following result disclosure, leading to ad-hoc modification of screening advice. For this reason, as well as to avoid intercounselor variation, we have selected five genetic counselors with many years of experience in oncogenetic counseling to see all patients participating in this study (both DNA-direct and DNA-intake).

In conclusion, the aim of our study is to determine whether DNA-direct is an acceptable procedure for $B R C A 1 / 2$ testing, in order to provide customized care to patients with breast cancer and remove unnecessary waiting times within the diagnostic process, cutting down on the long period of uncertainty that patients are currently faced with.

\section{Competing interests}

The authors declare that they have no competing interests.

\section{Acknowledgements}

The authors would like to acknowledge the contributions of M.F.W.J. Ariaans, H.J. van der Looij and M. Voorendt as genetic counselors, and P. Manders for main biostatistical expertise. The authors would also like to acknowledge H.W. te Winkel-Slotboom, J.J. van Tol-Geerdink, I. van Oostrom and J. Molenaar for their advice regarding the study questionnaires, and A.R.T. Donders for additional biostatistical expertise. The study is funded by the Radboud University Nijmegen Medical Centre from the Netherlands.

\section{Author details}

'Department of Human Genetics, Radboud University Nijmegen Medical Centre, Nijmegen, the Netherlands. 'Department of Medical Psychology, Radboud University Nijmegen Medical Centre, Nijmegen, the Netherlands.

\section{Authors' contributions}

$\mathrm{NH}$ and JBP have contributed to the study protocol and revised the manuscript. ASS has contributed to the study protocol and wrote the manuscript. LS, WAGZS, ARM, MJL and HGB have contributed to the study protocol. All authors have read and approved the final manuscript.

Received: 21 December 2011 Accepted: 8 May 2012

Published: 8 May 2012

\section{References}

1. Peters E, McCaul KD, Stefanek M, Nelson W: A heuristics approach to understanding cancer risk perception: contributions from judgment and decision-making research. Ann Behav Med 2006, 31:45-52.

2. Antoniou A, Pharoah PD, Narod S, Risch HA, Eyfjord JE, Hopper JL, Loman N, Olsson $\mathrm{H}$, Johannsson $\mathrm{O}$, Borg $\mathrm{A}$, et al: Average risks of breast and ovarian cancer associated with BRCA1 or BRCA2 mutations detected in case Series unselected for family history: a combined analysis of 22 studies. Am J Hum Genet 2003, 72:1117-1130.

3. Chen S, Parmigiani G: Meta-analysis of BRCA1 and BRCA2 penetrance. J Clin Oncol 2007, 25:1329-1333.

4. King MC, Marks JH, Mandell JB: Breast and ovarian cancer risks due to inherited mutations in BRCA1 and BRCA2. Science 2003, 302:643-646.

5. Audeh MW, Carmichael J, Penson RT, Friedlander M, Powell B, Bell-McGuinn KM, Scott C, Weitzel JN, Oaknin A, Loman N, et al: Oral poly(ADP-ribose) polymerase inhibitor olaparib in patients with BRCA1 or BRCA2 mutations and recurrent ovarian cancer: a proof-of-concept trial. Lancet 2010, 376:245-251.

6. Fong PC, Boss DS, Yap TA, Tutt A, Wu P, Mergui-Roelvink M, Mortimer P, Swaisland H, Lau A, O'Connor MJ, et al: Inhibition of poly(ADP-ribose) polymerase in tumors from BRCA mutation carriers. N Engl J Med 2009, 361:123-134.

7. Schwartz MD, Lerman C, Brogan B, Peshkin BN, Halbert CH, DeMarco T, Lawrence W, Main D, Finch C, Magnant C, et al: Impact of BRCA1/BRCA2 counseling and testing on newly diagnosed breast cancer patients. J Clin Oncol 2004, 22:1823-1829.

8. Silva E: Genetic counseling and clinical management of newly diagnosed breast cancer patients at genetic risk for BRCA germline mutations: perspective of a surgical oncologist. Fam Cancer 2008, 7:91-95.

9. Trainer AH, Lewis CR, Tucker K, Meiser B, Friedlander M, Ward RL: The role of BRCA mutation testing in determining breast cancer therapy. Nat Rev Clin Oncol 2010, 7:708-717.

10. Tutt A, Robson M, Garber JE, Domchek SM, Audeh MW, Weitzel JN, Friedlander M, Arun B, Loman N, Schmutzler RK, et al: Oral poly(ADP-ribose) polymerase inhibitor olaparib in patients with BRCA1 or BRCA2 mutations and advanced breast cancer: a proof-of-concept trial. Lancet 2010, 376:235-244.

11. Hermsen BB, Olivier RI, Verheijen RH, van Beurden M, de Hullu JA, Massuger LF, Burger CW, Brekelmans CT, Mourits MJ, de Bock GH, et al: No efficacy of annual gynaecological screening in BRCA1/2 mutation carriers; an observational follow-up study. Br J Cancer 2007, 96:1335-1342.

12. Hogg $R$, Friedlander M: Biology of epithelial ovarian cancer: implications for screening women at high genetic risk. J Clin Oncol 2004, 22:1315-1327.

13. van der Velde NM, Mourits MJ, Arts HJ, de Vries J, Leegte BK, Dijkhuis G, Oosterwijk JC, de Bock GH: Time to stop ovarian cancer screening in BRCA1/2 mutation carriers? Int J Cancer 2009, 124:919-923.

14. Domchek SM, Friebel TM, Singer CF, Evans DG, Lynch HT, Isaacs C, Garber JE, Neuhausen SL, Matloff E, Eeles R, et al: Association of risk-reducing surgery in BRCA1 or BRCA2 mutation carriers with cancer risk and mortality. JAMA 2010, 304:967-975.

15. Rebbeck TR, Kauff ND, Domchek SM: Meta-analysis of risk reduction estimates associated with risk-reducing salpingo-oophorectomy in BRCA1 or BRCA2 mutation carriers. J Natl Cancer Inst 2009, 101:80-87.

16. Bylund CL, Fisher CL, Brashers D, Edgerson S, Glogowski EA, Boyar SR, Kemel $Y$, Spencer $S$, Kissane D: Sources of uncertainty about daughters' breast cancer risk that emerge during genetic counseling consultations. J Genet Couns 2011, 21:292-304.

17. Kriege M, Brekelmans $C T$, Boetes $C$, Besnard PE, Zonderland HM, Obdeijn IM, Manoliu RA, Kok T, Peterse H, Tilanus-Linthorst MM, et al: Efficacy of MRI and mammography for breast-cancer screening in women with a familial or genetic predisposition. N Engl J Med 2004, 351:427-437.

18. Warner E, Plewes DB, Hill KA, Causer PA, Zubovits JT, Jong RA, Cutrara MR, DeBoer G, Yaffe MJ, Messner SJ, et al: Surveillance of BRCA1 and BRCA2 mutation carriers with magnetic resonance imaging, ultrasound, mammography, and clinical breast examination. JAMA 2004, 292:1317-1325.

19. Kurian AW, Sigal BM, Plevritis SK: Survival analysis of cancer risk reduction strategies for BRCA1/2 mutation carriers. J Clin Oncol 2010, 28:222-231.

20. Meijers-Heijboer $H_{\text {, van }}$ Geel B, van Putten WL, Henzen-Logmans SC, Seynaeve C, Menke-Pluymers MB, Bartels CC, Verhoog LC, van den Ouweland AM, Niermeijer MF, et al: Breast cancer after prophylactic 
bilateral mastectomy in women with a BRCA1 or BRCA2 mutation. N Engl J Med 2001, 345:159-164.

21. Rebbeck TR, Friebel T, Lynch HT, Neuhausen SL, Van't Veer L, Garber JE, Evans GR, Narod SA, Isaacs C, Matloff E, et al: Bilateral prophylactic mastectomy reduces breast cancer risk in BRCA1 and BRCA2 mutation carriers: the PROSE Study Group. J Clin Oncol 2004, 22:1055-1062.

22. Werner-Lin A: Beating the biological clock: the compressed family life cycle of young women with BRCA gene alterations. Soc Work Health Care 2008, 47:416-437

23. Henselmans I, Sanderman R, Smink A, Ranchor AV, de VJ: Waiting times in breast disease clinics and psychological well-being: speedy care is better care. Ned Tijdschr Geneeskd 2010, 154:B491

24. Kievit $W$, de Bruin $J H$, Adang EM, Severens $J$, Kleibeuker JH, Sijmons RH, Ruers TJ, Nagengast FM, Vasen HF, van Krieken JH, et al: Cost effectiveness of a new strategy to identify HNPCC patients. Gut 2005, 54:97-102.

25. Overbeek LI, Hermens RP, van Krieken JH, Adang EM, Casparie M, Nagengast FM, Ligtenberg MJ, Hoogerbrugge N: Electronic reminders for pathologists promote recognition of patients at risk for Lynch syndrome: clusterrandomised controlled trial. Virchows Arch 2010, 456:653-659.

26. Landsbergen KM, Prins JB, Brunner HG, Kraaimaat FW, Hoogerbrugge N: Genetic testing for Lynch syndrome in the first year of colorectal cancer: a review of the psychological impact. Fam Cancer 2009, 8:325-337.

27. Landsbergen KM, Prins JB, Brunner HG, Hoogerbrugge N: Genetic testing offered directly after the diagnosis of colorectal cancer: a pilot study on the reactions of patients. Genet Couns 2009, 20:317-325.

28. Landsbergen KM, Prins JB, Brunner HG, Hoogerbrugge N: Shortened time interval between colorectal cancer diagnosis and risk testing for hereditary colorectal cancer is not related to higher psychological distress. Fam Cancer 2011, 10:51-57.

29. Berliner JL, Fay AM: Risk assessment and genetic counseling for hereditary breast and ovarian cancer: recommendations of the National Society of Genetic Counselors. J Genet Couns 2007, 16:241-260.

30. Harper PS: What do we mean by genetic testing? J Med Genet 1997, 34:749-752.

31. U.S. Preventive Services Task Force: Genetic risk assessment and BRCA mutation testing for breast and ovarian cancer susceptibility: recommendation statement. Ann Intern Med 2005, 143:355-361.

32. van Oostrom I, Tibben A: A Counselling Model for BRCA1/2 Genetic Susceptibility Testing. Hered Cancer Clin Pract 2004, 2:19-23.

33. Andrews L, Meiser B, Apicella C, Tucker K: Psychological impact of genetic testing for breast cancer susceptibility in women of Ashkenazi Jewish background: a prospective study. Genet Test 2004, 8:240-247.

34. Braithwaite D, Emery J, Walter F, Prevost AT, Sutton S: Psychological impact of genetic counseling for familial cancer: a systematic review and metaanalysis. Fam Cancer 2006, 5:61-75.

35. Hamilton JG, Lobel M, Moyer A: Emotional distress following genetic testing for hereditary breast and ovarian cancer: a meta-analytic review. Health Psychol 2009, 28:510-518.

36. Heshka JT, Palleschi C, Howley H, Wilson B, Wells PS: A systematic review of perceived risks, psychological and behavioral impacts of genetic testing. Genet Med 2008, 10:19-32.

37. Meiser B: Psychological impact of genetic testing for cancer susceptibility: an update of the literature. Psychooncology 2005, 14:1060-1074.

38. Schlich-Bakker KJ, ten Kroode HF, Ausems MG: A literature review of the psychological impact of genetic testing on breast cancer patients. Patient Educ Couns 2006, 62:13-20.

39. Halbert CH, Stopfer JE, McDonald J, Weathers B, Collier A, Troxel AB, Domchek S: Long-term reactions to genetic testing for BRCA1 and BRCA2 Mutations: does time heal women's concerns? J Clin Oncol 2011, 29:4302-4306.

40. Pieterse AH, Ausems MG, van Dulmen AM, Beemer FA, Bensing JM: Initial cancer genetic counseling consultation: change in counselees' cognitions and anxiety, and association with addressing their needs and preferences. Am J Med Genet A 2005, 137:27-35.

41. Kessels RP: Patients' memory for medical information. J R Soc Med 2003, 96:219-222

42. Metcalfe KA, Poll A, Llacuachaqui M, Nanda S, Tulman A, Mian N, Sun P, Narod SA: Patient satisfaction and cancer-related distress among unselected Jewish women undergoing genetic testing for BRCA1 and BRCA2. Clin Genet 2010, 78:411-417.
43. Gilpin CA, Carson N, Hunter AG: A preliminary validation of a family history assessment form to select women at risk for breast or ovarian cancer for referral to a genetics center. Clin Genet 2000, 58:299-308.

44. Frank TS, Deffenbaugh AM, Reid JE, Hulick M, Ward BE, Lingenfelter B, Gumpper KL, Scholl T, Tavtigian SV, Pruss DR, et al: Clinical characteristics of individuals with germline mutations in BRCA1 and BRCA2: analysis of 10,000 individuals. J Clin Oncol 2002, 20:1480-1490.

45. Claus EB, Risch N, Thompson WD: The calculation of breast cancer risk for women with a first degree family history of ovarian cancer. Breast Cancer Res Treat 1993, 28:115-120.

46. van Asperen CJ, Jonker MA, Jacobi CE, van Diemen-Homan JE, Bakker E, Breuning $\mathrm{MH}$, van Houwelingen JC, de Bock $\mathrm{GH}$ : Risk estimation for healthy women from breast cancer families: new insights and new strategies. Cancer Epidemiol Biomarkers Prev 2004, 13:87-93.

47. Bottomley A, Aaronson NK: International perspective on health-related quality-of-life research in cancer clinical trials: the European Organisation for Research and Treatment of Cancer experience. J Clin Oncol 2007, 25:5082-5086

48. Luo N, Fones CS, Lim SE, Xie F, Thumboo J, Li SC: The European Organization for Research and Treatment of Cancer Quality of Life Questionnaire (EORTC QLQ-c30): validation of English version in Singapore. Qual Life Res 2005, 14:1181-1186.

49. Goldberg DP, Gater R, Sartorius N, Ustun TB, Piccinelli M, Gureje O, Rutter C The validity of two versions of the GHQ in the WHO study of mental illness in general health care. Psychol Med 1997, 27:191-197.

50. Goldberg DP, Oldehinkel T, Ormel J: Why GHQ threshold varies from one place to another. Psychol Med 1998, 28:915-921.

51. Krespi Boothby MR, Hill J, Holcombe C, Clark L, Fisher J, Salmon P: The accuracy of HADS and GHQ-12 in detecting psychiatric morbidity in breast cancer patients. Turk Psikiyatri Derg 2010, 21:49-59.

52. Horowitz M, Wilner N, Alvarez W: Impact of event scale: a measure of subjective stress. Psychosom Med 1979, 41:209-218.

53. van der Ploeg E, Mooren TT, Kleber RJ, van der Velden PG, Brom D: Construct validation of the Dutch version of the impact of event scale. Psychol Assess 2004, 16:16-26.

54. Hopwood P, Shenton A, Lalloo F, Evans DG, Howell A: Risk perception and cancer worry: an exploratory study of the impact of genetic risk counselling in women with a family history of breast cancer. J Med Genet 2001, 38:139.

55. Lerman C, Trock B, Rimer BK, Jepson C, Brody D, Boyce A: Psychological side effects of breast cancer screening. Health Psychol 1991, 10:259-267.

56. Lerman C, Daly M, Masny A, Balshem A: Attitudes about genetic testing for breast-ovarian cancer susceptibility. J Clin Oncol 1994, 12:843-850.

57. Koedoot N, Molenaar S, Oosterveld P, Bakker P, de Graeff A, Nooy M, Varekamp I, de Haes $\mathrm{H}$ : The decisional conflict scale: further validation in two samples of Dutch oncology patients. Patient Educ Couns 2001, 45:187-193.

58. O'Connor AM: Validation of a decisional conflict scale. Med Decis Making 1995, 15:25-30.

59. User Manual - Decisional Conflict Scale (16 item statement format). [http:// decisionaid.ohri.ca/docs/develop/User_Manuals/UM_Decisional_Conflict.pdf].

60. Berg Svd, Gielissen MF, Prins JB: Validation of an empowerment questionnaire in breast cancer survivors [abstract]. 12th World Congress of Psycho-Oncology 2010.

61. van Oostrom I, Meijers-Heijboer H, Lodder LN, Duivenvoorden HJ, van Gool AR, Seynaeve C, van der Meer CA, Klijn JG, van Geel BN, Burger CW, et al: Long-term psychological impact of carrying a BRCA1/2 mutation and prophylactic surgery: a 5-year follow-up study. J Clin Oncol 2003, 21:3867-3874.

doi:10.1186/1472-6874-12-12

Cite this article as: Sie et al:: DNA-testing for BRCA1/2 prior to genetic counselling in patients with breast cancer: design of an intervention study, DNA-direct. BMC Women's Health 2012 12:12. 